\title{
Steven B. Leder, PhD
}

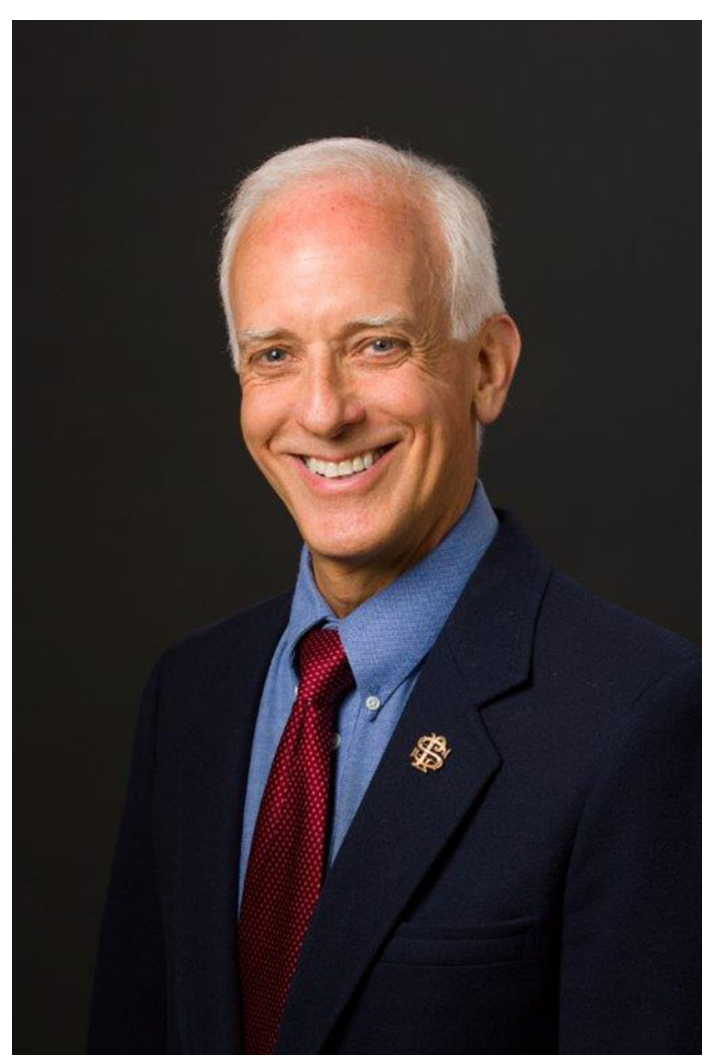

I write with sad news that our colleague and Associate Editor of Dysphagia journal, Steven B. Leder, PhD., passed away suddenly on Monday May 16, 2016. Dr. Leder joined the Yale School of Medicine in The Department of Surgery, Section of Otolaryngology in 1992 as an Assistant Professor and was promoted as Professor in 1999. He was a busy clinician, and has widely published particularly in the area of dysphagia. He was passionate in his devotion to The Dysphagia Research Society of which he served as the President, and to his journal, Dysphagia, serving as its Associate Editor and co-contributor to a popular editorial section, Comments, a commentary on the state of dysphagia research. His was the voice of unrestrained enthusiasm or unbridled disappointment. (Mine was to keep us out of trouble with the Publisher), as we struggled through the 1st draft of each copy.

Steve spent the early part of his career dispelling common myths and proving others wrong (me included). As he developed his own set of discoveries, he felt the pressure of others who challenged his positions, but openly and with grace, he embraced the process he knew necessary in the pursuit of truth.

I have seen in no other of my recruited faculty such a degree of open self-recognition that the power within himself derived from the power he received from others around him. That he valued these interactions was evidenced by the support he gave back to us, his professional colleagues, and students. He was the very best example of a valued faculty member.

At the time of his death, his achievements included 138 publications and books, the last of which was recently released: The Yale Pharyngeal Residue Severity Rating Scale: An Anatomically Defined and Image Based Tool. His passing is a tremendous loss to the Dysphagia community at our Institution, nationally and internationally.

Clarence T. Sasaki

The Charles W. Ohse Professor of Surgery

Yale School of Medicine 